Gut and Liver, Vol. 9, No. 4, July 2015, pp. 435-436

EDITORIAL

\title{
Confrontational Strategy Is Essential for Being Effective Precut Papillotomy
}

\author{
Sang-Heum Park and Tae Hoon Lee \\ Division of Gastroenterology, Department of Internal Medicine, Soonchunhyang University School of Medicine, Cheonan, Korea
}

See "Different Strategies for Transpancreatic Septotomy and Needle Knife Infundibulotomy Due to the Presence of Unintended Pancreatic Cannulation in Difficult Biliary Cannulation” by Yoon Jung Lee, et al. on page 534, Vol. 9. No. 4, 2015

Precut papillotomy (PP) is a useful technique for overcoming a difficult biliary cannulation (DBC). Various techniques and devices have been introduced for successful PP. ${ }^{1-3}$ PP using needle-knife (NK) is the main modalities, and PP using pull-type papillotome, transpancreatic septotomy (TPS), was firstly introduced by Goff in 1995. ${ }^{4}$ After then TPS with or without guidewire or/and pancreatic stent were compared with PP using NK. ${ }^{5-7}$

Even though TPS is useful in cases of unintended pancreatic cannulation in aspect of time and cost, TPS is not popular technique on the base of published articles until now. Recently Lee et al. ${ }^{8}$ reported affirmative results that contribute to raising the concern of TPS. They performed prospective study in which TPS was compared with NK infundibulotomy (NKI) in 86 patients in whom wire-guided cannulation had failed due to the DBC criteria. The initial total success rate of biliary cannulation was 88.4\% (86.6\% for the TPS group and 94.7\% for the NKI group, $\mathrm{p}=0.447$ ). After crossover of the techniques, the final success rate was $95.3 \%$ and the complication rate was $20.9 \%$ in patients with TPS and 15.8\% in patients with NKI ( $p=0.753$ ).

The study by Lee et al. ${ }^{8}$ pointed out the importance of a confrontational strategy for being successful PP. The main goal of PP is to enhance the success rate of biliary cannulation. Pancreatic duct cannulation is relatively frequent during endoscopic retrograde cholangiopancreatography (ERCP), especially in cases of DBC. ${ }^{5}$ It means that it will be more practical or/and useful if easy technique to lead to successful biliary cannulation in cases of unintended pancreatic cannulation is proposed as step-wise method. ${ }^{9}$ A presented strategy by Lee et al., ${ }^{8}$ was on base of the presence of unintended pancreatic cannulation. If pancreatic duct was cannulated over 3 times, TPS was initially applied. If both biliary and pancreatic duct were not selected, NKI was performed. The final success rate of selective biliary cannulation was $95.3 \%$, relatively superior to those reported in other studies. $^{5-8}$

Another big issue in PP is the safety in aspect of post-ERCP pancreatitis (PEP). ${ }^{1,10} \mathrm{PP}$ is relatively risky so that TPS in previous reports was followed by placing pancreatic stent for minimizing PEP. ${ }^{5-7}$ Even though pancreatic stent was not inserted after TPS in the study by Lee et al., ${ }^{8}$ the overall incidence of PEP was no statistically significant difference between the two groups, 10.4\% (7/67) in the TPS group and 5.3\% (1/19) in the NKI group. This means that TPS may be safe as NKI which has been approved of the safe technique despite of pros and cons. ${ }^{1,2,10}$ TPS may be a risk factor for PEP if pancreatic juice passage is disturbed. As the authors mention, this study is small cohort study in low-risk group. More large scaled studies are warranted to confirm it.

The proper timing of PP is another strategy. Both the NK precut procedure and ongoing repeated attempts at cannulation of the ampulla of Vater have been reported to be independent procedure-related risk factors for PEP, together with pancreatic duct cannulation and contrast injection. The advantage of early implementation of PP had been proposed constantly. ${ }^{1,3,9,10}$ Lee et al. ${ }^{8}$ applied stricter DBC criteria to prevent frequent papillary contacts causing PEP (5 minutes of attempted cannulation or more than three attempted unintended pancreatic cannulations) and added further evidence that the early PP is useful in aspect of minimizing PEP. In addition meaningful papillary contacts is also an important risk factor for PEP. If frequent papillary contacts persist more than 10 to 15 cannulation attempts without unintentional pancreatic cannulation regardless of time, early NKI can be considered to reduce PEP.9,10

Correspondence to: Sang-Heum Park

Division of Gastroenterology, Department of Internal Medicine, Soonchunhyang University Cheonan Hospital, Soonchunhyang University School of Medicine, 31 Soonchunhyang 6-gil, Dongnam-gu, Cheonan 330-721, Korea

Tel: +82-41-570-3892, Fax: +82-41-574-5762, E-mail: pparksh@schmc.ac.kr pISSN 1976-2283 eISSN 2005-1212 http://dx.doi.org/10.5009/gnl15203

@ This is an Open Access article distributed under the terms of the Creative Commons Attribution Non-Commercial License (http://creativecommons.org/licenses/by-nc/4.0) which permits unrestricted non-commercial use, distribution, and reproduction in any medium, provided the original work is properly cited. 
$\mathrm{PP}$ is a critical procedure to become an expert in performing an ERCP. The strategy in PP introduced by Lee et al. ${ }^{8}$ may be helpful to reach that goal, especially for those who are inexperienced with ERCP. In addition, for the enhancing biliary access and decrease the incidence of PEP, more strict stepwise guidelines for cannulation and use of prophylactic pancreas duct stent; insertion time, type, and duration, are needed.

\section{CONFLICTS OF INTEREST}

No potential conflict of interest relevant to this article was reported.

\section{REFERENCES}

1. Sriram PV, Rao GV, Nageshwar Reddy D. The precut: when, where and how? A review. Endoscopy 2003;35:S24-S30.

2. ASGE Technology Committee, Kethu SR, Adler DG, et al. ERCP cannulation and sphincterotomy devices. Gastrointest Endosc 2010;71:435-445.

3. Park SH, Park do H, Lee TH, et al. Feasibility of the mucosatracking technique in precut papillotomy with the iso-tome as an alternative to the needle-knife technique. Gut Liver 2010;4:76-83.

4. Goff JS. Common bile duct pre-cut sphincterotomy: transpancre- atic sphincter approach. Gastrointest Endosc 1995;41:502-505.

5. Catalano MF, Linder JD, Geenen JE. Endoscopic transpancreatic papillary septotomy for inaccessible obstructed bile ducts: comparison with standard pre-cut papillotomy. Gastrointest Endosc 2004;60:557-561.

6. Wang $\mathrm{P}$, Zhang W, Liu F, et al. Success and complication rates of two precut techniques, transpancreatic sphincterotomy and needle-knife sphincterotomy for bile duct cannulation. J Gastrointest Surg 2010;14:697-704.

7. Chan CH, Brennan FN, Zimmerman MJ, Ormonde DG, Raftopoulos SC, Yusoff IF. Wire assisted transpancreatic septotomy, needle knife precut or both for difficult biliary access. J Gastroenterol Hepatol 2012;27:1293-1297.

8. Lee YJ, Park YK, Lee MJ, Lee KT, Lee KH, Lee JK. Different strategies for transpancreatic septotomy and needle knife infundibulotomy due to the presence of unintended pancreatic cannulation in difficult biliary cannulation. Gut Liver 2015;9:534-539.

9. Lee TH, Hwang SO, Choi HJ, et al. Sequential algorithm analysis to facilitate selective biliary access for difficult biliary cannulation in ERCP: a prospective clinical study. BMC Gastroenterol 2014;14:30.

10. Dumonceau JM, Andriulli A, Elmunzer BJ, et al. Prophylaxis of post-ERCP pancreatitis: European Society of Gastrointestinal Endoscopy (ESGE) Guideline - updated June 2014. Endoscopy 2014; 46:799-815. 